\title{
An embedded microcontroller unit for PV module monitoring and fault detection
}

\author{
P. Borza*1 \\ ${ }^{1}$ Department of Electronics \& Computers \\ Transilvania University of Brasov \\ Brasov, Romania \\ borzapn@unitbv.ro
}

\author{
E. Kaplani ${ }^{2}$ \\ ${ }^{2}$ Engineering, Faculty of Science \\ University of East Anglia \\ Norwich, UK \\ e.kaplani@uea.ac.uk
}

\begin{abstract}
This paper presents the architectural lay-out and functional design details of a microcontroller embedded electronic monitoring system (e-EMS). According to the design, this unit is integrated into the PV module junction box. It can be scaled up to form part of a complex PV power plant control system. The communication topology follows a 3-tier structure. It uses two processors, one dedicated for data acquisition and the other for communication purposes. The e-EMS provides a complete set of data associated to PV module performance characteristic parameters, including current and voltage of the PV module and each sub-string of cells, operation of the bypass diodes along with the corresponding current and voltage measurements, PV temperature and environmental parameters. The sampling rate can be programmed in a large range from 1 to $65 \mathrm{~s}$ along with the number of samples used for averaging signal values. The power output is determined every hour, as a basic output of the system. Comparison of the determined values with the expected ones when normalized to the PV operating conditions provides reliable information on deviation trends, the degree of degradation that the PV module experiences, while the analysis of the sampled data may identify the cells or modules which experience degradation and disclose types of factors which affect their operation.
\end{abstract}

Keywords-embedded electronic monitoring system; DAQ; network topology; PV monitoring; PV degradation

\section{INTRODUCTION}

The performance of PV modules the fundamental unit of a PV array or plant depends on many factors that may be external, as for example the intensity of the solar radiation incident on the PV modules, $\mathrm{I}_{\mathrm{T}}$, the wind velocity, $\mathrm{v}_{\mathrm{w}}$, the ambient temperature, $\mathrm{T}_{\mathrm{a}}$, shadowing patterns on the modules, etc. or internal such as micro-cracks, corrosion, delamination, EVA browning, finger interruptions, etc. [1-4]. Internal factors responsible for PV degradation may be caused by external parameters or created during the cell manufacturing process, such as micro-cracks and crystal micro-defects, weak regions in the metallization, shunts either ohmic, especially in the lateral sides of the cells due to passivation problems or shunt diodes which represent $\mathrm{e}^{-}$- hole recombination centres in the cell structure [5-8]. All these factors significantly affect the PV power output $\mathrm{P}_{\mathrm{m}}$, the current $\mathrm{I}$ and voltage $\mathrm{V}$ at the maximum power point MPP, the Fill Factor, the module efficiency, the series and shunt resistances [9-11]. The effect may be temporary as in the case of transient shadows casted on the PV modules or permanent as in the case of corrosion, delamination, etc. In the latter case their impact may increase during the lifetime of the PV module, while the degradation and aging of the PV cells becomes a governing factor in the PV power performance [12-14].

Continuous monitoring of the operation of grid-connected PV systems is necessary to ensure optimal energy harvesting and reliable power production. Efforts in developing advanced monitoring and diagnostic methods and tools for PV fault detection are acknowledged throughout the world and are of particular importance because of the rapid increase of PV installations and the need to optimize and sustain their performance. The research projects in the above domain fall into 4 categories:

1. electric based methods and tools. Monitoring of fundamental electrical quantities of a module, string of modules, arrays and plant, comparison with the expected values and I-V curve analysis to proceed to fault detection and diagnostics [15-23]

2. Artificial intelligence, Neural Networks, Fuzzy logic, time series and stochastic analysis using accumulated data [24-28]

3. PV power forecasting methodologies and comparison with measured or estimated values to evaluate the PV systems degradation, and predict the power to be delivered during the hours of the day with emphasis in the time domain for the control system to take appropriate decisions in matching the load profiles [29-34]

4. IR image analysis, I-V curve analysis, and other NDT tools to identify spatiotemporally the defected modules and cells $[35,36]$.

Due to the degradation factors affecting PV performance a wide interest is shown in the monitoring of the PV power output. Several works presented so far design details of the monitoring system and test results captured at the DC/AC output or the PV string of modules or the PV module itself [37-39]. The intention was to estimate the deviation of the PV power output from the expected value and if possible to identify which PV module(s) are affected, and provide 
information about the type of the degradation developed in the module. However, it is desirable to have more advanced monitoring tools available in order to provide reliable information on the performance quality of the modules or strings.

The objective of this project was to design and construct a cost-effective microcontroller unit embedded into the PV module either plugged-in or replacing the junction box with an intelligent version equipped additionally with sensors to provide reliable monitoring and full scale information on the electric quantities of the module, each string of cells, and in the by-pass diodes, as well as the module temperature $T_{c}$, and environmental data, solar irradiance incident on the PV plane $\mathrm{I}_{\mathrm{T}}$, ambient temperature $\mathrm{T}_{\mathrm{a}}$, wind speed $\mathrm{v}_{\mathrm{w}}$. The data monitored are required by the system for the on-line PV power analysis. PV performance deviations from the expected for the environmental conditions where the PV module operates may indicate different failure modes. For a reliable identification of the failure mode, it is important for the monitoring to take place at the module or even cell sub-string level. Scalability of the system is considered at design, being able to effectively monitor an entire PV installation.

\section{ARCHITECTURAL DESIGN}

\section{A. Design and Operational Principles}

The e-EMS is designed as modular unit. The architectural structure of the embedded micro-electronics PV module monitoring unit is based on the following design details and operational principles:

a. the analogue signal processing and insulation board (ASPIB) that permits adaptation of signal acquired for the main system digital board. This is attach to the main board (DAQ) as a piggy-back solution and can be interchanged with another card having different facilities;

b. the wired/ wireless connected data acquisition processing and communication board (DAQ) is able to signal acquisition, monitoring and determination of the electric parameters of the module $\mathrm{I}$ and $\mathrm{V}$ at the point of operation, $\mathrm{V}$ across each sub-string of cells $\mathrm{V}_{\text {str1 }}$, $\mathrm{V}_{\text {str2 }}, \mathrm{V}_{\text {str3 }}$, the current through each bypass diode $\mathrm{I}_{\mathrm{D} 1}$, $\mathrm{I}_{\mathrm{D} 2}$, $\mathrm{I}_{\mathrm{D} 3}$ (see Fig.1) and the temperature of a PV cell representing module temperature.

c. The DAQ includes an analogue to digital converter at high resolution (16 or 24 bits resolution) with 6 multiplexed channels, offset and full scale selfcalibration, connected by a SPI (Serial Peripheral Interface) with a new powerful micro-controller Atmega328P. The block diagram of the system is illustrated in Fig. 2.

d. The communication sub-system (COMM) uses a dedicated micro-processor to wirelessly transmit to a central data concentrator (CDC) the data sampled and process them to determine deviations and trends in order to estimate PV module degradation and identify possible failure modes. The link with the DAQ is implemented using UART serial bus. The board allows changing the wireless transceiver with another one, having the same standard form factor and pins. The HC05, JDY30 and HM10 transceivers were tested with similar communication parameters but compliant with different Bluetooth protocols BT2.0, BT3.0 and respectively BLE 4.2 (low energy) [40]. Also, for long range communication facility the NRF24LS01 transceiver was tested and its range in free field was tested at around $1000 \mathrm{~m}$ with a consumption less than 12-15mA. A wired serial interface compliant with RS232 (3.3V level) permits for short distances to have a connection to the supervisor implemented by wire. The DAQ also allows acquisition of another four multiplexed analogue signals. For this scope the microcontroller analogue to digital converters with 10 bits resolution, can be used to acquire analogue signals that are not galvanically insulated. The internal usable memory is around $1.6 \mathrm{~KB}$ where data acquired can be stored.

e. The sensors embedded in the DAQ system are Hall effect based current sensors with high accuracy (0.2$0.5 \%$ ) and optocouplers which are used in the linear zone of their characteristic and present a similar accuracy as a result of the full correction based on the experimental characteristics that are used. Periodical calibration to increase signal acquisition accuracy is carried out in order to keep measurement errors low. The sensors used ensure in the same time the galvanic insulation between the energetic circuits of the PV module and the embedded electronic system. The signal acquisition chain elements are all correlated as parameters in order to minimize all factors' errors and cost. As a function of the desired resolution one of two analogue to digital converters (MAX11253 or ADS124S06) can be used for signal conversion and acquisition. Is sigma -delta converters and by programming the sampling rate, the programmable gain and the internal voltage reference can be adequately settled.

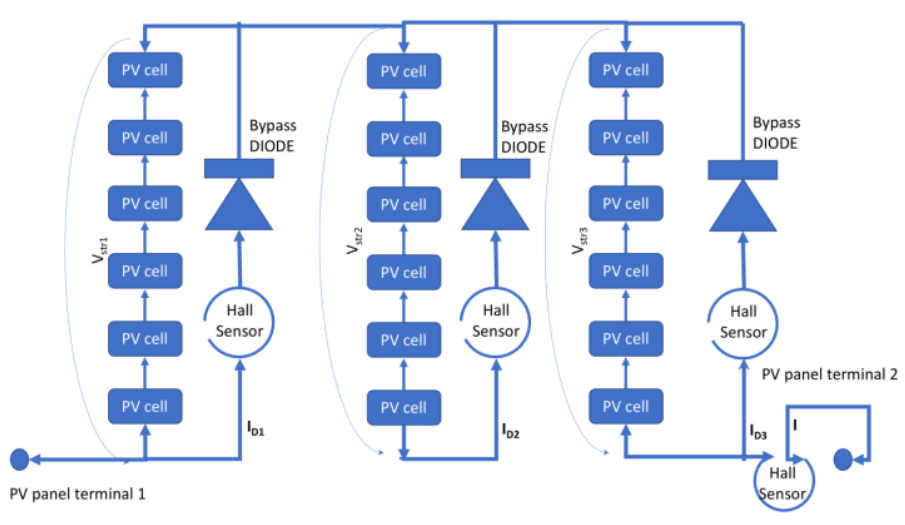

Fig. 1. PV module structure with 3 sub-strings and position of the current sensor 




Fig. 2. Block diagram of the e-EMS

\section{B. Functionality}

The functioning of the main e-EMS component which is the DAQ is based on an "event driven" model that permits the fast and specific response of the system at each request or event produced during its operation. Thus, the main event is related to the time measurement that will trigger the signal acquisition at low and high resolution (Fig.3), internal analog to digital converter, and external high-resolution ADC, respectively.

The signals acquired (Fig. 4) are buffered on internal SRAM data memory (2 kB), as mean values for a set number of samples/signal and, periodically at the initiative of CDC, the data buffers are uploaded to the central point. Additional signals from solar irradiance sensor, wind velocity and ambient temperature sensors are recorded centrally for the global parameters $\mathrm{I}_{\mathrm{T}}, \mathrm{T}_{\mathrm{a}}$, and $\mathrm{v}_{\mathrm{w}}$. On CDC the programs that run for the management of the entire solar power plant open for each component module several treads which manage the communication link, emit the necessary control telegrams, and receive corresponding echoes that contain the data acquired. The main functionalities supported are: selection of baud rate, automatic detection and configuration of the existing serial interfaces, processing and storage of data acquired, etc. as shown in Fig.5.

The Human Machine Interface (HMI) is simple, indicating directly only the necessary parameters and fully endowed to assure the complete customization of the acquisition process and configuration of the data acquisition system too.

The supplies are independent for the two components of the system: DAQ and COMM. In this way, it is easy to detect when one of the voltage power supply reaches the "brawn level" indicating the limit of its operation. The workflow diagram of the COMM and DAQ processors is shown in Fig.6.

The DAQ is programmed to pre-process the data acquired locally and determine the power output from each string and the module. Local values are transmitted to the CDC and compared to the nominal ones after normalizing the nominal values to the operational environmental conditions based on $\mathrm{I}_{\mathrm{T}}, \mathrm{T}_{\mathrm{a}}$, and $\mathrm{v}_{\mathrm{w}}$.

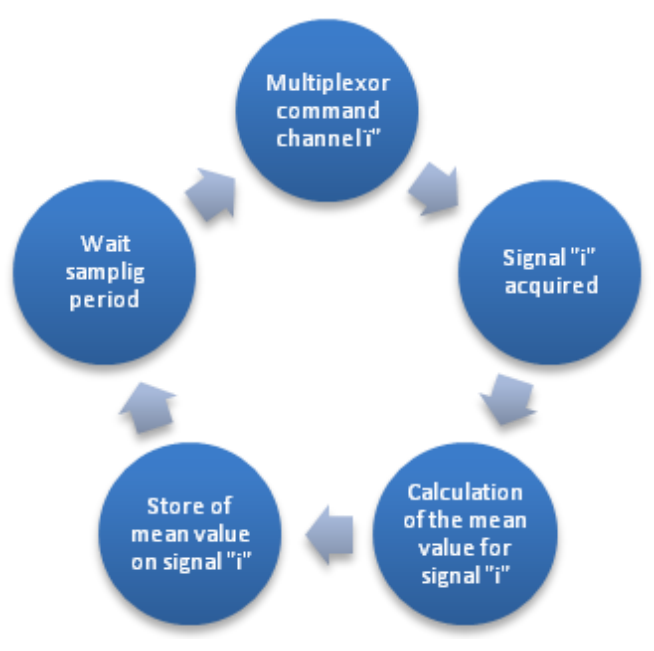

Fig. 3. Workflow of one signal acquisition

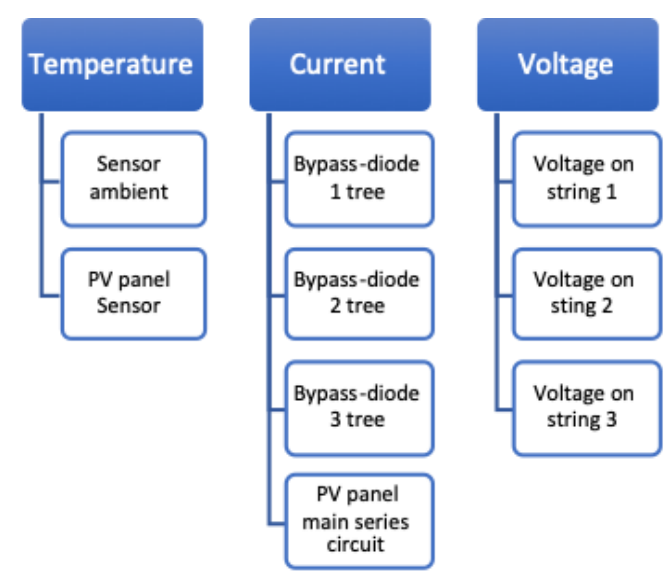

Fig. 4. Table with signals acquired 
Deviation of the module power output from the expected value triggers further temporal assessment of the local values at the central point to determine the type of failure (eg. partial shading, dust accumulation, or more permanent degradation effects such as corrosion of busbars, contacts, delamination, etc.).

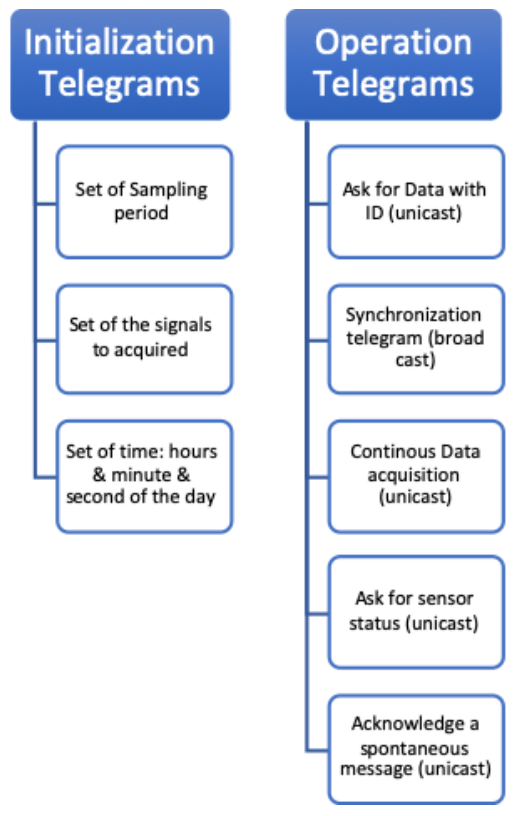

Fig. 5. Main telegrams that assure the management of PV panel monitoring system

The Panasonic 18650 3350mAh batteries for DAQ and ML2020 for the COMM module were used. The overall consumption of e-EMS is less than $40 \mathrm{~mA}$ and this assures independence in supplying more than 3 and a half days without any power management action and overpass one year when the power management is used. Future improvements include implementation of a recharging system for Panasonic battery directly from the PV panel and replacing the ML2020 with a rechargeable battery.

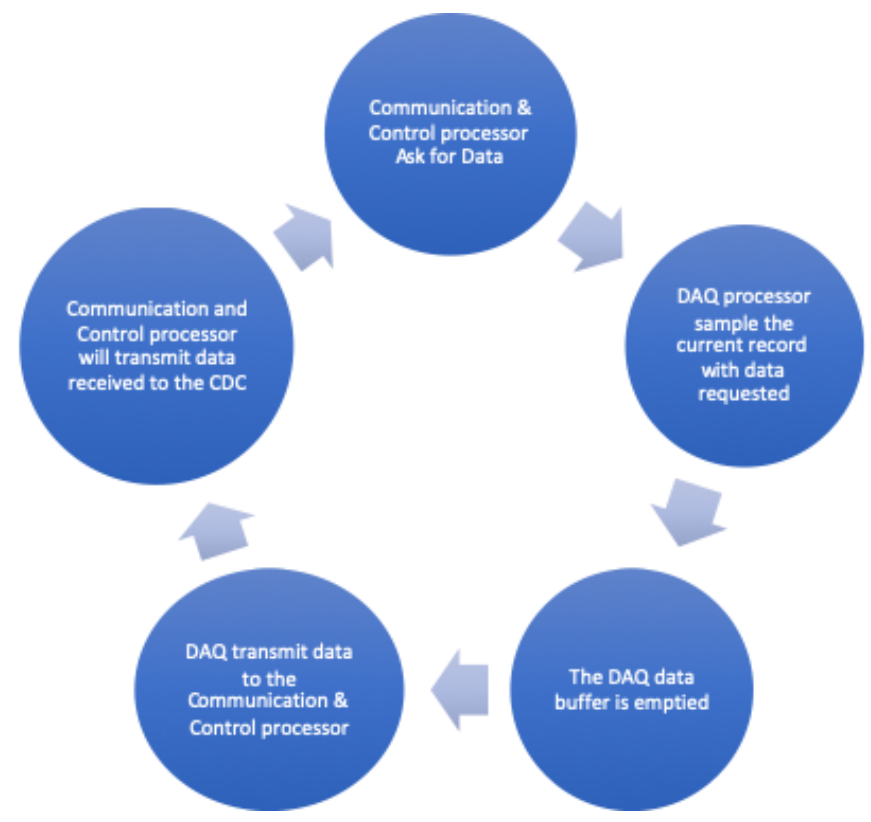

Fig. 6. Work-flow diagram for a data transaction between Communication \& Control processor and the DAQ processor

\section{PV PLANT NETWORK}

The acquisition network permits the integration of all data acquired from each PV panel and the internal cell sub-strings into a single database, creating a useful unique database covering the entire solar power plant system in its successive stages. This represents the basis for the development of the intelligent software module for solar power plant energy efficiency optimization and also for developing the preventive maintenance functionality. The topology of the network is illustrated in Fig. 7. Using two transceivers (Bluetooth and RFM) for integration of the e-EMS system for the case of a solar power plant, the topology shown in Figure 7 is more easily implemented, similarly to the retina organization [41].

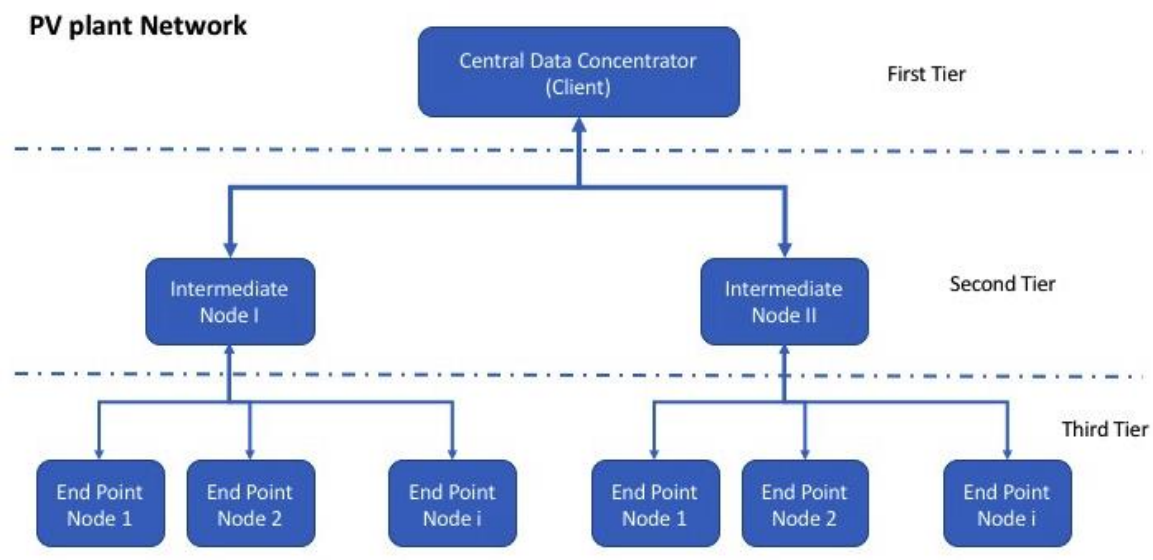

Fig. 7. Topology of the signal acquisition network corresponding to a solar power plant 


\section{THE EMBEDDED ELECTRONIC MONITORING SYSTEM (E-EMS UNIT)}

The e-EMS built is presented in Fig.8. The module is attached to an atmega328P microprocessor board. Two transceivers endow the COMM module in order to ensure two different settlements for the e-EMS module (interim of end node) into the power plant data acquisition network. The short-range transceiver is implemented by a Bluetooth Low Energy (BLE) module with a range of $10 \mathrm{~m}$, and the RFM transceiver can reach a range of more than $400 \mathrm{~m}$ with strip antenna. The maximum number of connections allowed by BLE transceiver is 7 and the RFM transceiver allow more than 65000 connections.

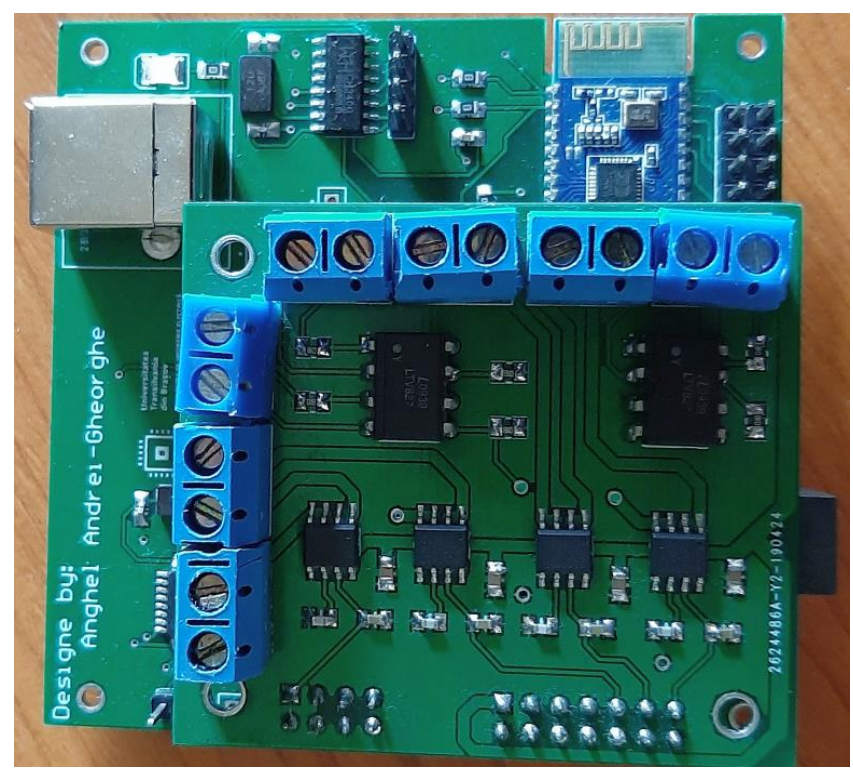

Fig. 8. Analogue signal processing and insulation board (ASPIB) connected by piggy-back to microprocessor board

\section{CONCLUSIONS AND FUTURE WORKS}

A novel e-EMS modular unit was built for the monitoring of PV modules in a PV power plant providing valuable information on the electric parameters of the PV modules down to the cell sub-string level, which allows the detection of failure modes and the estimation of PV degradation. The eEMS has low consumption, incorporates wireless sensors and communication protocol to assure the management of the PV module monitoring system. Additionally to the capabilities offered by existing systems, the proposed system is able to diagnose internal module failure characteristics linked to the cell sub-strings as it monitors the activation of the bypass diodes. Processing of this information allows the identification of the defected cells or sub-string of PV module. In the future the system will allow to replace the present bypass diodes by new short-circuit elements based on CMOS switching transistors. The current paper has presented the architectural design of the e-EMS system with the operational principles and designed functionality along with the topology of the signal acquisition network for the entire solar power plant.
Current work is carried out in the testing of the system and the identification of defects and failure modes. The module will reach the Internet of Thinks (IoT) features by developing the present firmware and improving further its functionalities.

\section{ACKNOWLEDGEMENT}

The authors express their thanks to Prof. S. Kaplanis for his valuable comments and discussions on the unit.

\section{REFERENCES}

[1] Kontges M. et al. "Review of failures of Photovoltaic Modules", External final report IEA_PVPS, Task 13, March 2014, ISBN 978-3-609042-16-9

[2] Jordan D.C., Kurtz S.R. "Photovoltaic Degradation Rates: An Analytical Review” NREL/JA-5200-51664, June 2012

[3] Kaplani E."Detection of Degradation Effects in Field-Aged c-Si Solar Cells through IR Thermography and Digital Image Processing" International Journal of Photoenergy, Vol. 2012, Article ID 396792, p.111. doi:10.1155/2012/396792

[4] Kaplani E. "PV cell and module degradation, detection and diagnostics" Renewable Energy in the Service of Mankind Vol II: Selected Topics from the World Renewable Energy Congress WREC 2014. Sayigh, A. (ed.). Switzerland: Springer International Publishing, p. 393-402.

[5] Breitenstein O., Rakotoniaina J.P., Al Rifai M. H., Werner M., "Shunt types in crystalline silicon solar cells" Progress in Photovoltaics, 2014.

[6] Breitenstein O., Bauer J., Altermatt P.P., Ramspeck K. "Influence of Defects on Solar Cell Characteristics" Solid State Phenomena, Vol.156158 (2010), pp1-10, Trans. Tech. Publications, Switzerland

[7] Croizier J., Van Dyk E.E., Vorster F. "Identification and characterisation of performance limiting defects and cell mismatch in photovoltaic modules" J. En. in Southern Africa 26(3)(2015)pp19-26, DOI: 10.17159/2413-3051/2015/v26i3a2126

[8] Van Dyk E., Meyer E. "Analysis of the effect of parasitic resistances on the performance of photovoltaic modules", Renew. Energy 29 (3) (2004),pp. 333-344.

[9] Acciani G., Vergura S. "Typical defects of PV Cells" 2010 IEEE International Symposium on Industrial Electronics, 2010, Bari, Italy, DOI:10.1109/ISIE.2010.5636901

[10] King D.L., Quintana M.A., Kratochvil J.A., Ellibee D.E, Hansen B.R., "Photovoltaic Module Performance and Durability Following Long-term Field Exposure” Prog. Photovolt: Res. Appl. 8 (2) (2000) 241-256.

[11] Munoz M., Alonso-García M.,Vela N., Chenlo F., "Early degradation of silicon PV modules and guaranty conditions", Sol. Energy 85 (9) (2011) 2264-2274

[12] Ndiaye A., Charki A., Cobi A. "Degradations of silicon photovoltaic modules: A literature review" Solar Energy 96(2013):140-151

[13] Kaplani E."Degradation effects in sc-Si PV modules subjected to natural and induced ageing after several years of field operation". Journal of Engineering Science and Technology Review, Special Issue on Renewable Energy Systems, 2012, Vol.5(4), p.18-23.

[14] Vazques M., Rey-Stolle I. "Photovoltaic module reliability model based on field degradation studies"Prog. Photovolt: Res. Appl. 2008; 16:419433

[15]Marion B. "Comparison Of Predictive Models for PV Module Performance" 33rd IEEE Photovoltaic Specialists Conference San Diego, CA, May 11-16, 2008, NREL/PO-520-43288

[16]Kilper T. et al. "A new generation of PV monitoring system with highgrade remote diagnostics based on module level monitoring and integrated yield simulation" 31st European Photovoltaic Solar Energy Conference and Exhibition, (EU PVSEC 2015), Hamburg, Germany, 1418 September, 2015

[17] Makrides G. et al. "Advanced performance monitoring system for improved reliability and optimized levelized cost of electricity" 32nd European Photovoltaic Solar Energy Conference and Exhibition, Munich, Germany, 20-24 June, 2016 
[18] Madeti S.R. S.N. Singh. "Monitoring system for photovoltaic plants: A review", 2017, Renewable and Sustainable Energy Reviews 67, pp.11801207 DOI: 10.1016/j.rser.2016.09.088

[19]Fernández-Pacheco DG, Molina-Martínez JM, Ruiz-Canales A, Jiménez M. A new mobile application for maintenance tasks in photovoltaic installations by using GPS data. Energy Convers Manage 2012; 57: 7985

[20]Marni R. et al "Accurate String Measurements for Solar PV Power Plants to improve the Performance and Reliability"IJERT, ISSN: 2278-0181 Vol. 5 Issue 10, October-2016

[21]Sahbel A et al. "Experimental Performance Characterization of Photovoltaic Modules Using DAQ” Energy Procedia 36 (2013) pp. 323332

[22]Rezgui W. et al. "Electrical faults detection for the intelligent diagnosis of a photovoltaic generator". HAL Id: hal-01154202 https://hal.archivesouvertes.fr/hal-01154202.

[23] Aworo O.J., Kwasinski A., 2018. "Fault detection strategy for grid-tie three-phase photovoltaic inverter. Proc. ICRERA 2018, 14-17 Oct., Paris, France.

[24]Rezgui, W., Mouss, H., Mouss, M.D., Kadri, O., 2014. Electrical faults detection for the intelligent diagnosis of a photovoltaic generator.J. Electrical Eng. 14 (1), 77-84.

[25]Spataru, S., Sera, D., Kerekes, T., Teodorescu, R., 2012. "Detection of increased series losses in PV arrays using fuzzy inference systems". In: Proceedings of the IEEE Photovoltaic Specialists Conference, Austin, TX, USA, June 3-8, pp. 464-469.

[26]Rezgui W. et al "Electrical faults detection for the intelligent diagnosis of a photovoltaic generator" HAL Id: hal-01154202 https://hal.archivesouvertes.fr/hal-01154202

[27]Bonsignore L. et al. "Neuro-Fuzzy fault detection method for photovoltaic systems” Energy Procedia 62 (2014), pp. 431 - 441

[28]Syafaruddin, E., Karatepe, T., Hiyama, 2011. "Controlling of artificial neural network for fault diagnosis of photovoltaic array". In: Proceedings of the International Conference on Intelligent System Application to Power Systems, Hersonissos, Greece, September 25-28, pp. 1-6.

[29] Mohamed A. H., Nassar A.M.. "New Algorithm for Fault Diagnosis of Photovoltaic Energy Systems" International Journal of Computer Applications, 114 (2015) 9
[30]Kalaitzakis K., Koutroulis E., Vlachos V."Development of a data acquisition system for remote monitoring of renewable energy systems"Measurement 34 (2003) pp.75-83

[31]Ventura C, Tina G.M "Development of Models for On-line Diagnostic and Energy Assessment Analysis of PV Power Plants: The Study Case of 1 MW Sicilian PV Plant", Energy Procedia 2015 83: 248-257 DOI: 10.1016/j.egypro.2015.12.179

[32] Cristaldi L. et al " A cooperative monitoring and diagnostic architecture for PV systems"978-1-4799-7250-0/16/\$31.00 @2016 IEEE

[33] Daliento S. et al."Monitoring, Diagnosis, and Power Forecasting for Photovoltaic Fields: A Review" International Journal of Photoenergy Vol. 2017, Article ID 1356851, 13 pages DOI: 10.1155/2017/1356851

[34] Davarifar M., Rabhi A., El-Hajjaji A., Dahmane M., 2013. "Real-time model base fault diagnosis of PV panels using statistical signal processing". Proc. ICRERA 2013, 20-23 Oct., Madrid, Spain.

[35]Hu Y. et al "Identifying PV Module Mismatch Faults by a ThermographyBased Temperature Distribution Analysis". IEEE Transactions on Device and Materials Reliability 14 (4), 951-960

[36]Sera, D., Teodorescu, R., Rodriguez, P., 2009. Partial shadowing detection based on equivalent thermal monitoring for PV module diagnostics. In: Proceedings of the Annual Conference of the IEEE Industrial Electronics Society, Porto, Portugal, Nov. 3-5, pp.708-713

[37] Chen Y.H., Liang R., , Tian Y.,Wang F. "A novel fault diagnosis method of PV based-on power loss and I-V characteristic" IOP Conf. Series: Earth and Environmental Science 40 (2016) 012022 doi:10.1088/1755$1315 / 40 / 1 / 012022$

[38]Nakai T. et al."Power drop detection in PV string by analyzing I-V characteristics"Journal of International Council on Electrical Engineering, 7:1, 7-14, DOI: 10.1080/22348972.2016.1273296

[39]Chevalley B. "Innovative Approaches to Solar PV plants' Asset Management and O\&M through Monitoring; AEG" Intersolar Summit, Turkey - Istanbul, 06/04/2016

[40] Borza P. N. Machedon-Pisu M., Hamza-Lup F., (2019). "Design of Wireless Sensors for IoT with Energy Storage and Communication Channel Heterogeneity", Sensors 2019, 19(15), 3364 ; https://doi.org/10.3390/s19153364

[41] Delgado-Gomes, V., Borza, P. N. (2014). "A biological approach for energy management in smart grids and hybrid energy storage systems". IOPTIM 2014. https://doi.org/10.1109/OPTIM.2014.6851039 